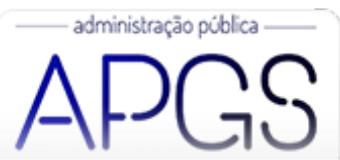

Administração Pública e Gestão Social ISSN: 2175-5787

apgs@ufv.br

Universidade Federal de Viçosa

Brasil

\title{
Inovação na Gestão Pública como "Possibilidade Objetiva": O Caso do Pacto pela Educação de Pernambuco sob a Ótica da Administração para o Desenvolvimento
}

\author{
Rani Ferreira de Sousa, Jessica \\ Inovação na Gestão Pública como "Possibilidade Objetiva": O Caso do Pacto pela Educação de Pernambuco sob \\ a Ótica da Administração para o Desenvolvimento \\ Administração Pública e Gestão Social, vol. 11, núm. 4, 2019 \\ Universidade Federal de Viçosa, Brasil \\ Disponível em: http://www.redalyc.org/articulo.oa?id=351560525005
}

Esta obra está bajo una Licencia Creative Commons Atribución-NoComercial-SinDerivar 3.0 Internacional. 


\title{
Inovação na Gestão Pública como "Possibilidade Objetiva”: O Caso do Pacto pela Educação de Pernambuco sob a Ótica da Administração para o Desenvolvimento
}

\author{
Innovation in Public Management as "Objective Possibility": The Case of Pact for Education in Pernambuco from \\ the Perspective of Administration for Development \\ Innovación en la Gestión Pública como "Posibilidad Objetiva": El Caso del Pacto por la Educación en Pernambuco \\ desde la Perspectiva de la Administración para el Desarrollo
}

Jessica Rani Ferreira de Sousa

Universidade Federal de Pernambuco, Brasil

Redalyc: http://www.redalyc.org/articulo.oa?

jessica.rani@ufpe.br

id $=351560525005$

Recepção: 31 Janeiro 2019

Aprovação: 14 Agosto 2019

Publicado: 01 Outubro 2019

\section{Resumo:}

O presente trabalho objetivou investigar como o Pacto pela Educação de Pernambuco (PPE) contribui para fomentar práticas que caracterizem inovações na gestão pela perspectiva da efetividade da política pública, adotando como lente teórica e sensibilizante a Teoria das Possibilidades de Guerreiro Ramos e sua abordagem sobre Administração para o Desenvolvimento. Por meio de estudo de caso qualitativo e de análise temática de conteúdo das entrevistas realizadas nos níveis estratégico e tático de sua operacionalização, puderam ser identificadas categorias concentradas em torno de práticas especificamente advindas com o PPE: O uso de indicadores de desempenho e a publicitação de descritores escolares, pela perspectiva do Sistema de Informações da Educação de Pernambuco (SIEPE), dos painéis de gestão e pela própria mídia. Os sinalizadores de efetividade identificados para essas categorias disseram respeito à criação de um olhar diferenciado para as escolas e alunos prioritários da rede pública, à credibilidade, transparência, percepção de empoderamento e ao aprimoramento da consciência sobre o contexto escolar.

PALAVRAS-CHAVE: Inovação na gestão pública, Administração para o Desenvolvimento, Pacto pela Educação de Pernambuco.

\section{Abstract:}

This paper aims to investigate how the Pact for Education in Pernambuco, Brazil, contributes to fostering practices that characterize management innovations from the perspective of public policies's effectiveness, adopting as theoretical and sensitizing lens the Theory of Possibilities by Guerreiro Ramos and its approach on Administration for Development. By means of a qualitative case study and thematic analysis of the content of the interviews carried out at the strategic and tactical levels of its operationalization, it was possible to identify categories concentrated around practices specifically related to the referred pact, such as the use of performance indicators and advertising of school descriptors. The effectiveness indicators identified for these categories relate to the creation of a differentiated look for the schools and priority students of the public system, credibility, transparency, perception of empowerment and improvement of awareness about the school context.

KEYWORDS: Public management innovation, Administration for Development, Pact for Eduucation in Pernambuco, Brazil.

\section{RESUMEN:}

El presente trabajo tuvo como objetivo investigar cómo el Pacto por la Educación en Pernambuco, un estado brasileño, contribuye a fomentar prácticas que caracterizan innovaciones en la gestión por la perspectiva de la efectividad de la política pública, adoptando como lente teórica y sensibilizante la Teoría de las Posibilidades de Guerreiro Ramos y su abordaje sobre Administración para el Desarrollo. Por medio de un estudio de caso cualitativo y de análisis temático de contenido de las entrevistas realizadas en los niveles estratégico y táctico de su operacionalización, pudieron ser identificadas categorías concentradas en torno a prácticas específicamente derivadas del Pacto, como el uso de indicadores de rendimiento y la publicidad de descriptores escolares. Los indicadores de efectividad identificados para esas categorías se refirieron a la creación de una mirada diferenciada a las escuelas y alumnos prioritarios de la red pública, credibilidad, transparencia, percepción de empoderamiento y perfeccionamiento de la conciencia sobre el contexto escolar.

Palabras Clave: Innovación en la gestión pública, Administración para el Desarrollo, Pacto pela Educação de Pernambuco. 


\section{INTRODUÇÃo}

Nos termos da Administração para o Desenvolvimento, vincular o desenvolvimento e a modernização das sociedades à mudança social constitui um dos mais relevantes caminhos para se compreender as diversas possibilidades de capacidade evolutiva dos Estados (Ramos, 1966; 1983a). Este trabalho parte do pressuposto de que a reinvenção do planejamento governamental e de determinadas políticas públicas seja uma alternativa pertinente a uma nova Administração para o Desenvolvimento. Dentro desta concepção, acredita-se que tais esforços poderiam vincular-se perfeitamente à adoção de inovações na gestão.

No escopo do Pacto pela Educação de Pernambuco (PPE), essas inovações encontram-se declaradamente voltadas ao fim último de melhoria da qualidade na prestação de serviços públicos de educação e, por consequência, ao desenvolvimento social. O PPE se volta para todas as escolas estaduais do ensino fundamental anos finais (EFAF) e de ensino médio (EM), por meio de um sistema autêntico de monitoramento de resultados. A esse sistema de monitoramento e acompanhamento por resultados, juntamente à ampliação da fatia orçamentária destinada à educação, via institucionalização do regime de colaboração por meio da Emenda Constitucional 59/2009, é que foram atribuídas expressivas taxas de crescimento do Índice de Desenvolvimento da Educação Básica (Ideb) para o Ensino Médio em Pernambuco nos últimos anos ${ }^{[\mathrm{i}]}$.

Tomando como referência alguns trabalhos acadêmicos relativos à educação já realizados no campo da gestão pública, ressalta-se a grande lacuna percebida quanto à descrição de práticas que pudessem efetivamente caracterizar ou configurar o fenômeno da inovação na gestão. Cabe dizer que as que se aproximam deste campo de investigação limitam-se à ênfase no modelo de gestão por resultados e alguns de seus pilares, tais como a avaliação por desempenho e sua política de monitoramento, como em Lemos (2009) e Patriota (2014), na discussão sobre a capacidade do núcleo estratégico da gestão do governo na contratualização de resultados de políticas públicas (Correia, 2011), ou mesmo na avaliação de resultados da política educacional como um todo e seu impacto (Germano, 2015). Para o caso das pesquisas que compartilham especificamente do PPE como objeto de estudo, também constatou-se que o foco recai sobre alguma escola ou um grupo de escolas específicas, caso de Oliveira (2014), ou ainda sobre parte da política do PPE, como em Santiago (2014), que analisa a rede de educação integral.

Considerando como pressuposto o escopo maior de desenvolvimento dos estados por meio da educação e o princípio da efetividade como indicador de valor fundamental para a Administração Pública (Motta, 1972), o presente trabalho objetivou investigar se o PPE contribui para fomentar práticas que caracterizem, de fato, inovações na gestão, adotando como lente teórica a Teoria das Possibilidades (Ramos, 1983a; 1983b) e a abordagem guerreirista sobre gestão e desenvolvimento. Assim, a problemática ora exposta buscou responder a seguinte pergunta de pesquisa: Como práticas inovadoras de gestão no âmbito do Pacto pela Educação de Pernambuco podem configurar-se como "possibilidades objetivas" de desenvolvimento?

É válido mencionar que, para os resultados do projeto de pesquisa da qual este trabalho é parte, a princípio, partiu-se do entendimento de inovação na gestão a partir de uma noção geral de "mudança de status quo" (Hamel, 2006), também referente ao uso de novos instrumentos políticos, decorrentes de alterações substanciais em políticas de gestão (Halvorsen, 2005), ou, ainda, a um conjunto de novos métodos de organização de responsabilidades, do processo decisório e das relações externas adotadas pela gestão pública (Bloch, 2010), incluindo práticas como a fruição de redes informais de inovação, a utilização de indicadores e metas de desempenho e iniciativas de participação popular na tomada de decisóes públicas (Dias, 2014). Para responder à pergunta de pesquisa exposta anteriormente, a Administração para o Desenvolvimento e a Teoria das Possibilidades foram tomados como conceitos sensibilizantes das pressuposições da pesquisa empírica e na análise dos dados obtidos com a investigação.

$\mathrm{Na}$ seção a seguir recuperam-se alguns dados importantes para o melhor conhecimento desta política educacional, visando melhor caracterizá-la para, em sequência, apresentar o referencial teórico que embasou a 
discussão sobre a perspectiva guerreirista revisitada na literatura. A terceira seção explicita os procedimentos metodológicos utilizados na pesquisa. Já no quarto e principal tópico, são analisadas as inovações identificadas como possibilidades objetivas de desenvolvimento, de acordo com as concepções teórico-metodológicas que orientaram o estudo. $\mathrm{O}$ trabalho é concluído apresentando suas principais considerações finais, limitações e sugestões para investigações futuras.

\section{Sobre o objeto do qual este trabalho toma parte: As práticas inovadoras de gestão no Âmbito do Pacto pela EducaÇão de Pernambuco}

A escolha do Pacto pela Educação como escopo de análise sobre dimensões práticas da inovação na gestão no âmbito da Administração Pública justifica-se pela prerrogativa da ideia de educação como prática libertadora (Freire, 2000; Sen, 2010) e de sua primazia para o desenvolvimento da cidadania, para o desenvolvimento econômico e para a modernização das sociedades. Além de consagrada a relação entre desenvolvimento e educação, como propõe Cavalcanti (2011), ressalta-se também o poder democratizante desta, tendo em vista as diversas políticas públicas educacionais e o peso de reformas administrativas que as afetaram, sobretudo por meio de programas de modernização da gestão nos últimos anos.

Os dados que dão subsídio a políticas públicas de educação no Brasil, ao invés de indicarem a mudança pretendida há várias décadas pela Administração do Desenvolvimento, exibem um cenário desolador (Arretche, Fusaro \& Gomes, 2012). Conforme relatório do Programa Internacional de Avaliação de Estudantes (Pisa) ${ }^{[i i]}$ de 2015, o score médio dos estudantes brasileiros apresenta valor significativamente inferior à média dos estudantes dos países membros da OCDE em todas as categorias abrangidas pela avaliação trienal (Ciências, Leitura e Matemática). De modo alarmante, as séries históricas dos dados coletados no Brasil também não trouxeram evidências empíricas que apontem diferenças estatisticamente significativas entre o desempenho dos estudantes brasileiros em Ciências no Pisa de 2015 e das três últimas edições da avaliação, nem entre o desempenho em Leitura nas edições da avaliação desde 2000 (Instituto Nacional de Estudos e Pesquisas Educacionais Anísio Teixeira - Inep, 2016). O Brasil ainda se encontra abaixo da média que se espera de um sistema educacional de qualidade comparável ao de países considerados desenvolvidos (cujo índice médio é 6,0). Em 2017, a média do Ideb na rede pública de educação observada para os anos finais do Ensino Fundamental foi de 4,4 e para o Ensino Médio, de 3,5 (Inep, 2019).

Em Pernambuco, o PPE foi oficialmente implementado em 2011. Como política pública pertencente a um Modelo de Gestão Integrada ("Todos por Pernambuco") ${ }^{[i i i]}$, o PPE desdobra objetivos estratégicos relativos à melhoria da qualidade da educação pública e à formação profissional em metas pactuadas pela Secretaria de Educação e pelo governo do estado. O sistema de monitoramento por meio de indicadores de resultados no qual se pauta é operacionalizado por meio de avaliações diretas de desempenho realizadas junto às escolas estaduais e aos próprios estudantes. Foi formalizado com o Decreto Estadual no 39.336 de 2013, pelo qual foram estabelecidas as diretrizes para os Programas de Gestão por Resultados com geração de Valor Público. Conforme seu artigo $7^{\circ}$, os Pactos de Resultados, como é o caso do Pacto pela Educação, constituem "metodologias específicas de Gestão por Resultados aplicadas em programas multisetoriais, previstos no Mapa da Estratégia do governo com a finalidade de obter a melhoria em indicadores de qualidade dos serviços públicos".

Até o início de 2017, a política envolvia um total de 768 escolas de todas as regiões do estado, monitoradas por meio de um sistema mensal de metas por um Painel de Avaliação de Resultados estabelecido para todos os anos do Ensino Médio. Vale pontuar que até o final de 2015 o PPE direcionava-se apenas a escolas de ensino médio, quando, a partir de então, foram introduzidas no plano as EFAFs, mesma época em que se iniciaram as parcerias do governo do estado com alguns municípios (SEPLAG, 2018).

Fundamentais para a reestruturação da rede de gestão escolar demandada para o funcionamento do Pacto foram a adoção do Sistema de Avaliação Educacional de Pernambuco (SAEPE) e a criação do Bônus de 
Desempenho Escolar (BDE). O SAEPE nivelou uma grade curricular mínima em toda a rede de escolas vinculadas ao Pacto, aferindo anualmente o desempenho das escolas. Já o BDE premia com um décimo quarto salário os profissionais de escolas que alcançarem as metas de melhoria previstas pelo SAEPE (Pernambuco, 2015).

O sistema de acompanhamento dos resultados do PPE ocorre por meio de reuniões que abrangem todos os níveis de ação do governo junto à Secretaria de Planejamento e Gestão do estado (SEPLAG) e à Secretaria de Educação (SEE), até alcançar as Gerências Regionais de Educação (GREs) e inclusive as equipes das escolas vinculadas ao Pacto. Junto com sua implementação, as mudanças mais significativas relativas a essa política de educação diz respeito à implantação de uma política diferenciada de "responsabilização educacional", por meio da definição de basicamente dois tipos de indicadores trabalhados no nível da gestão: Indicadores de Processo e Indicadores de Resultado (SEPLAG, 2018).

Os indicadores de processo são mensurados pela frequência discente e docente, razão entre o número de aulas previstas e aulas dadas, cumprimento dos conteúdos curriculares, número de estudantes abaixo da média e inclusive a taxa de participação familiar nas reuniões escolares. Já os indicadores de resultado são aqueles que são oficialmente publicados como saldo do processo. Os mais representativos são o Ideb e Índice de Desenvolvimento de Educação de Pernambuco (IDEPE), este último aferido pela prova do SAEPE, em Língua Portuguesa e Matemática (SIEPE, 2017). O IDEPE é um indicador exclusivo de Pernambuco, semelhante ao Ideb, porém avaliado em um intervalo de tempo menor (um ano) e de forma censitária, em todas as escolas do estado, enquanto que o Ideb é avaliado a cada dois anos, de forma amostral (algumas escolas são selecionadas para a realização da prova).

Acrescentam-se a essa lista os chamados "Indicadores de impacto", mais difíceis de mensurar e menos divulgados junto à comunidade escolar. Esses últimos são trabalhados mais especificamente pela SEPLAG e obtidos principalmente junto à Agência Estadual de Planejamento e Pesquisas de Pernambuco (CONDEPE/ FIDEM), autarquia de pesquisa e estudos com dados estatísticos.

Além do trabalho com indicadores e metas, outra mudança consubstancial advinda junto com o Pacto que merece ser ressaltada como pedra de toque para a sustentabilidade de novas práticas na gestão foi o movimento em direção à modernização do sistema utilizado por toda a rede estadual para divulgação de descritores escolares e das notas dos alunos. O Sistema de Informações da Educação de Pernambuco (SIEPE), ferramenta de suporte ao professor na web, foi implantado em 2012 e é alimentado por professores e educadores de apoio, além de contar com ambientes integrados de informações da "Gestão da Rede de Ensino", "Gestão de Programas Educacionais" e um ambiente "pedagógico" (Pernambuco, n.d.).

A ideia de investigar "práticas inovadoras na gestão" tomando a Administração para o Desenvolvimento como conceito sensibilizante advém também de uma das quatro perspectivas presentes no corrente Mapa da Estratégia de governo do estado de Pernambuco, programado para o período 2015-2018, ora definida como "Gestão Participativa e Transformadora”. Nos termos do Relatório Anual das Ações do Governo publicado em 2015, tal gestão deve ser "capaz de gerar resultados para a sociedade através do desenvolvimento contínuo do Modelo de Gestão do Estado e do apoio aos municípios, explicitando aspectos da Gestão Participativa e Inovadora implantada" (Pernambuco, 2015, p. 11).

Tomando como conceito sensibilizante a ótica guerreirista das possibilidades, seria possível vislumbrar a inovação na gestão como uma possiblidade objetiva de mudança e de desenvolvimento? Mais que isso, compreendida a gestão do desenvolvimento como um objeto de interesse coletivo (Santos, Santos \& Braga, 2015), incluindo nessa seara a sociedade civil e os governos, seria possível entender a inovação como uma possibilidade genuína para a efetividade das políticas públicas e, por conseguinte, para a transformação social por intermédio da gestão pública? É nesse sentido que o presente trabalho se propõe a discutir a temática da inovação na gestão, investigando a literatura pertinente a mudanças consubstanciais na forma de gerir a política pública, que possam vir a ser consideradas como possibilidades objetivas para o desenvolvimento. 


\section{Revisitando a Perspectiva Guerreirista sobre o "Desenvolvimento das Possibiliddades"}

Por seu posicionamento ideológico e suas contribuições às ciências sociais, Alberto Guerreiro Ramos é considerado um dos pioneiros nos estudos críticos em Administração no Brasil (Ramos, 1981; Nery \& Peixoto, 2013; Santos et al., 2015), bem como um dos mais importantes expoentes autores na literatura de incorporação de esforços para constituição de uma disciplina de Administração para o Desenvolvimento no campo da Gestão Pública. Um olhar especial à crítica guerreirista justifica-se, como bem apontado por Santos et al. (2015), na preocupação do cientista social em relacionar, já na década de 1960, o fenômeno da gestão com o desenvolvimento das nações.

Integrando as discussões a respeito de estágios de modernização dos países e sobre o fenômeno da modernização como mudança social, está a abordagem de Ramos (1983a) sobre o "Desenvolvimentos das Possibilidades", na qual são contrapostas duas teorias, denominadas “Teoria N" e “Teoria P". A Teoria N corresponde à visão clássica de desenvolvimento que, por muito tempo, alimentou o pensamento de que as nações periféricas deveriam se espelhar nos países desenvolvidos, para alcançar o progresso social conforme seus parâmetros e estratégias de modernização. Desta forma, a Teoria $\mathrm{N}$ valida uma compreensão unilinear de evolução, pertinente à ideia de progresso, apontando o desenvolvimento como resultado de um curso de causas e efeitos decorrentes de um conjunto de ações que se dá em etapas, de modo que as sociedades possam alcançar a modernização.

A Teoria P, por sua vez, considera que o curso dos acontecimentos deriva continuamente de uma gama de fatores objetivos e opções humanas. Defende que só é possível tomar decisões e compreender o processo social de forma incremental. É essa teoria que tem como decorrente a proposta guerreirista de "desenvolvimento das possibilidades". Uma das proposições importantes da Teoria P é que nenhum curso de acontecimentos deveria ser considerado resultante da ação recíproca de causas absolutamente necessárias. Desta forma, é possível, sim, fazer previsões, sujeitas, porém, a um grau variável de certeza, dependendo de algumas circunstâncias concretas (Ramos, 1983a), tais como condições políticas, econômicas e sociais (Motta, 1972).

O "desenvolvimento das possibilidades" é, pois, defendido como teoria alternativa aos modelos de desenvolvimento sectário e de desenvolvimento utópico, considerando a capacidade de cada contexto para encontrar seus próprios caminhos (Ramos, 1983a; 1983b). Mais uma vez, ressalta-se que o processo de modernização a ser seguido pelas nações que almejam desenvolver-se social e economicamente não deve, na ótica do desenvolvimento das possibilidades, ser orientado por arquétipos ou modelos prontos a serem transferidos ou adaptados aos países em desenvolvimento.

A Teoria P é, por assim dizer, coerente com a perspectiva de que a modernidade ou a imagem de progresso associada às nações desenvolvidas, concebidas sob o crivo sociológico evolutivo, é falaciosa, já que "indicadores de modernização só os poderá haver ad hoc, e sua natureza e aplicação somente têm sentido quando postas em relação com as possibilidades de desenvolvimento ou modernização de cada sociedade" (Ramos, 1983a, p. 18).

Em síntese, analisar os limiares que se encontram na fronteira entre o determinismo e a liberdade implica refletir sobre todas as possibilidades de desenvolvimento de uma nação, considerando as possibilidades objetivas existentes nesse meio (Santos et al., 2015), em outras palavras, "escolher dentro de certos limites" (Ramos, 1983a, p. 8). Assim, a teoria das possibilidades de desenvolvimento vem para salientar que a evolução histórica de um país, região ou estado não está presa a padrões passados nem muito menos a padrões externos de desenvolvimento, mas, pelo contrário, sempre há possibilidades de mudança genuínas (Heidmann \& Salm, 2009).

Vislumbrar o desenvolvimento pelo prisma de possibilidades objetivas significa "converter possibilidades concretas em ação" (Ramos, 1983b, p. 38). Na descrição de mais uma das proposições da Teoria P, tais 
possibilidades não são abstratas, exatamente por se associarem, necessariamente, a uma situação concreta, e serem passíveis de demonstração empírica (Ramos, 1983a).

A concepção de desenvolvimento advinda da Teoria $\mathrm{P}$ encontra-se intimamente ligada à engenhosidade de administradores públicos ou administradores do desenvolvimento na formulação de estratégias voltadas para a melhoria das políticas governamentais, esforço que não se limita à conformidade aos interesses institucionalizados dominantes (Ramos, 1983b). Apesar das considerações sobre a tão aclamada mudança social como máxima envergadura da ação administrativa atualizante (Ramos, 1966), nota-se uma carência ainda eminente de discussões teóricas sobre soluções estratégicas que possibilitem, nesse sentido, efetivamente "dirigir e implementar a mudança" (Bennis, 1966 citado por Ramos, 1983a, p. 25).

Embora não se refira diretamente à inovação na gestão pública, ao discorrer sobre o futuro da Administração Pública na América Latina, o próprio Ramos (1983b) ressalta a necessidade de renovação nas práticas administrativas, e de modelos de gestão que atendam ao imperativo de desenvolvimento humano e de remodelação do sistema macrossocial. Consciente de que, na grande maioria das práticas administrativas ainda prevaleçam modelos obsoletos de organização e burocracia, o autor ressalta um dilema que desafia a disciplina da Administração para o Desenvolvimento, bem como o ofício do próprio administrador público: "De um lado, poderosas pressóes que procuram a manutenção do status quo; de outro, o imperativo de renovação social em larga escala" (p. 42).

Por outro lado, para demarcar essa necessidade de renovação como "possibilidade genuína" - tal qual referenciam Heidman \& Salm (2009), Ramos (1983b) destaca ainda que a Administração do Desenvolvimento deve começar em casa e valida as observações de Thompson (1964), por ele citado, quanto à necessidade de uma administração "adaptativa", especialmente para os países considerados periféricos, e de um "clima de inovação" na Administração Pública:

A prática e os princípios administrativos do Ocidente derivam de uma preocupação com controle, e por isto têm pouco valor para a Administração do Desenvolvimento em países subdesenvolvidos, onde há necessidade de uma administração adaptativa, capaz de incorporar constantes mudanças. [...] Como exemplos de tais princípios, vale mencionar: um clima de inovação [grifo nosso]; operacionalização e compartilhamento de objetivos; combinação de planejamento (pensar) e ação (fazer); minimalização de provincialismos; difusão de influência; maior tolerância para com a independência; evitar a buropatologia (Ramos, 1983b, p. 44).

\section{Procedimentos Metodológicos Adotados nesta Pesouisa}

Tomando o caso do PPE como uma política cujo sistema encontra-se delimitado por fronteiras identificáveis (Godoy, 2006), esta pesquisa caracteriza-se como um estudo de caso qualitativo, tendo como intenção captar os significados latentes de uma situação que está em foco (Creswel, 2010), e como concepção epistemológica a percepção de como os indivíduos constroem a realidade em interação com seus mundos sociais (Merriam \& Tisdell, 2016).

Sem desconsiderar as deficiências ainda latentes na educação pública do estado, o reconhecimento internacional do modelo de gestão e os índices de desempenho que colocaram o estado de Pernambuco em um cenário de destaque nacional nos anos de 2013, 2014 e 2015 fazem do PPE um caso "representativo" segundo as considerações de (Yin, 2005) - para capturar e descrever práticas inovadoras de gestão em políticas públicas.

Os instrumentos de coleta de dados envolveram, a princípio, análise documental e análise de fontes diversas da chamada "literatura cinzenta" (Flick, 2013), enquadrando-se em uma etapa primária de investigação a consulta a relatórios técnicos do Governo do Estado, além de dados das páginas institucionais da SEPLAG e da SEE do estado, bem como arquivos e artigos publicados referentes ao Modelo de Gestão "Todos por PE” (do qual o PPE é parte). Também foram consultados slides de apresentações institucionais do PPE, disponibilizados pela SEPLAG, Cartilhas de treinamento do Programa de Formação Continuada de 
Gestores Escolares de Pernambuco (PROGEPE), Balanços da Educação da SEE-PE, bem como as legislações pertinentes ao Modelo de Gestão Integrada e ao Pacto pela Educação, e seus respectivos marcos legais. Ressalta-se que a concepção de corpus aqui adotada remete à coleção dos arquivos que compuseram o recurso geral de investigação para análise secundária (Bauer \& Aarts, 2002).

O aprimoramento do corpus se deu com os dados obtidos mediante realização de 18 entrevistas semiestruturadas, realizadas no período compreendido entre outubro de 2016 a janeiro de 2017, considerando respondentes dos dois níveis de ação do governo do estado - estratégico e tático - responsáveis pela operacionalização das estratégias gerais do PPE junto a escolas consideradas prioritárias e pelo sistema de monitoramento de resultados dessa política. Os principais atores que integram esses níveis são gestores da SEPLAG (Gestores Governamentais), da SEE (Secretário Estadual de Educação e Secretários Executivos) e das GREs (Gerentes Regionais e Coordenadores Setoriais de Educação).

Para a seleção de gestores regionais, de acordo com proposta de Bauer \& Aarts (2002), foram considerados os critérios de relevância, considerando as GREs com maior crescimento percentual do IDEPE acumulado no período compreendido entre 2008 e $2015^{\text {[iv] }}$ (GREs Metropolitana Norte, Recife Norte e Agreste Meridional) e, secundariamente, os critérios de representatividade e conveniência durante o período de realização das entrevistas. A representatividade foi relativa à quantidade de escolas abrangidas pela GRE e a conveniência, relativa ao acesso à GRE e à possibilidade de agendamento para observação, considerando também a disponibilidade de gestores regionais e de coordenadores para o agendamento de entrevistas mais a oportunidade de compreender diferentes posições de sujeito (não apenas gestores das GREs com alto índice acumulado de IDEPE). Segundo ambos os critérios foram selecionadas mais duas GREs (Recife Sul e Agreste Centro Norte).

Para a seleção dos Coordenadores Setoriais, seguiu-se o critério da relevância, sendo entrevistados seis Coordenadores das GREs elencadas segundo o mesmo critério, na seguinte disposição de Coordenações Setoriais: Gestão de Rede (2), Desenvolvimento da Educação (2), Administração e Finanças (1) e Educação Profissional (1). Os respondentes da SEPLAG e da SEE foram entrevistados conforme o critério da conveniência. Foram entrevistados três gestores governamentais da Unidade de Gestão por Resultados da SEPLAG. Os três Secretários Executivos das Secretarias de apoio da SEE de Pernambuco (SEE-PE) foram pertencentes, respectivamente, à Secretaria Executiva de Educação Profissional; Secretaria Executiva de Administração e Finanças e Secretaria Executiva de Planejamento e Coordenação, além do próprio Secretário Estadual de Educação.

O quadro total de respondentes foi dividido em três estratos, identificados nos discursos dos respondentes (A - Gestores governamentais, B - Secretário de Educação e Secretários Executivos, C - Gerentes Regionais e Coordenadores Setoriais), por entender-se como uma informação útil na compreensão das práticas inerentes a cada contexto dos níveis tático e estratégico de gestão do PPE.

Como técnica de análise dos dados coletados das entrevistas, foi utilizada a análise temática de conteúdo (Bardin, 1977; Gomes, 1994). Nesta pesquisa, a análise temática foi direcionada a desvelar os núcleos de sentido a partir da definição de "unidades de contexto" com base naquilo indicado por Bardin (1977) para a sua delimitação. A Administração para o Desenvolvimento e a Teoria das Possibilidades foram tomadas como conceitos sensibilizantes para a criação das categorias, segundo indicado por Charmaz (2006).

Conforme apontado por Blumer (1969), os conceitos sensibilizantes constituem suposições e perspectivas prévias assumidas pelo pesquisador, que auxiliam na modelagem de tópicos importantes para sua investigação e para o enfoque conceitual adotado a priori em seu trabalho. É oportuno lembrar que eles oferecem um ponto de partida e não de chegada, podendo vir à tona no processo de codificação e análise de dados e prover uma oportunidade de disciplinar o desenvolvimento de ideias posteriores, mas não de limitá-las (Charmaz, 2006).

A partir da seção seguinte, destacamos como algumas das práticas identificadas nos níveis tático e estratégico do PPE puderam responder à pergunta de pesquisa, por meio da identificação de duas categorias emergentes do campo, orientada pelos conceitos sensibilizantes adotados. Essa categorias concentraram-se 
em uma análise apurada em torno de práticas especificamente advindas com o PPE e aqui consideradas inovadoras no sentido de caracterizar "possibilidades objetivas" de mudança e conduzir a estratégias eficazes de modernização.

\section{A inovaÇÃo como possibilidade objetiva sob a ótica da AdMinistraÇão para o Desendolvimento: Algumas práticas do PPE EM análise e Seus sinalizadores de EFETIVIDADE}

Para o caso do PPE, a proposta de descrever inovações na gestão como "possibilidades objetivas" de desenvolvimento considerou como critério a indicação de mudanças que pudessem refletir determinados sinais de efetividade da política pública. Conforme já pontuado anteriormente, esse critério constitui indicador de valor especial para as ações da Administração Pública (Motta, 1972) e preceito fundamental para uma gestão que se diz voltada ao desenvolvimento (Motta \& Schmitt, 2013). É importante pontuar que a ideia de efetividade, neste sentido, tem a ver com a racionalidade substantiva e valorativa discutida por Ramos $(1966,1981)$ e toma forma quando os objetivos da Administração Pública coadunam com objetivos de desenvolvimento econômico e social. Em outros termos, quando o comprometimento instituído por determinadas estratégias ou práticas de gestão são mais sensivelmente percebidas como um valor da Administração para o Desenvolvimento.

As práticas analisadas a seguir - o uso de indicadores de desempenho e a publicitação de descritores escolares ou dos resultados do Pacto - pela perspectiva do SIEPE, dos painéis de gestão e pela própria mídia foram consideradas inovadoras, levando em conta os sinais de efetividade das mesmas pela ótica da gestão, especialmente para o contexto e a comunidade escolar. À medida que essas categorias foram analisadas, também foram descritos os principais sinalizadores de efetividade identificados.

\subsection{O Uso de indicadores}

Em relação ao uso dos indicadores, inerentes ao sistema de monitoramento do Pacto, percebe-se um conjunto de implicações variadas em função do tipo de indicador trabalhado: De processo ou de resultado, também incluindo neste campo os descritores escolares de desempenho. Neste sentido, o principal sinalizador de efetividade observado pela perspectiva da gestão se traduz na criação de um olhar diferenciado para as escolas e para os alunos prioritários da rede pública.

São denominadas "prioritárias" as escolas que obtiveram resultados inferiores a uma nota de corte estabelecida pela SEE e validada junto à SEPLAG. Os parâmetros para definição dessa nota de corte são definidos com base na média nacional do Ideb e também na evolução do IDEPE para o período. Enquanto que os alunos "prioritários" são determinados pelo rendimento insatisfatório dos descritores de desempenho individual. A demarcação de escolas prioritárias permite, a priori, uma destinação de recursos melhor fundamentada:

Então hoje nós temos um conjunto de escolas, que chamamos de "escolas prioritárias" e quando nós temos um recurso que precisamos iniciar pra algum lugar, nós iniciamos pelas escolas... E pelas regionais [GREs] que precisam melhorar o resultado. Então influencia não só aspectos mais conceituais de gestão, influencia a parte mais pragmática da gestão, que é a aplicação de recursos (Entrevista B.3).

Tal olhar diferenciado proporciona valorar a prática do uso de indicadores não apenas em termos de eficiência (destinação dos recursos) e eficácia (aferição de desempenho), mas em termos de relevância, na qual se assenta a racionalidade administrativa da Administração para o Desenvolvimento. Tal relevância implica considerar a escala de valores e as condições políticas e econômicas do meio em questão (Motta, 1972). A identificação das escolas e dos alunos chamados de "prioritários” também implica em um acompanhamento 
preciso o suficiente para identificar as GREs cujas respectivas escolas demandam atenção especial da gestão ou maiores esforços pedagógicos, referentes a reforço escolar ou estratégias diferenciadas de aprendizagem. As escolas prioritárias, nesse aspecto, podem identificar exatamente os pontos que precisam melhorar para sair dessa condição e obter melhor desempenho:

Porque ela enxergava que melhorar Matemática não é melhorar Matemática, é melhorar o determinado descritor [...]. Às vezes não estava acompanhando porque naquela região tem uma carência enorme, né? Do ensino fundamental, e às vezes precisava fazer um trabalho maior de reforço escolar [...]. Então, cada escola passou a construir o seu próprio diagnóstico, a sua própria visão. Mas pra isso a gente precisava chegar pra ela e dizer “ó, tá aqui os dados, se conheça mais", e aí isso, na minha opinião, fez toda diferença no trabalho (Entrevista B.1).

Nesse caso, a possibilidade está em ter disponíveis instrumentos de gestão que permitam uma atuação direcionada da gestor. Ao dar sentido à agência, quando o mesmo percebe que "melhorar Matemática" significa melhorar determinado descritor referente à disciplina, o olhar possibilitado pelo uso de indicadores acaba por conclamar o lado de não neutralidade dos gestores como agentes ativos de ações de transformação (Ramos, 1966). A possibilidade em si não garante que esse acompanhamento será sempre feito de forma tempestiva, porém permite, objetivamente, determinar padrões e prioridades de atuação na política pública e, coincidentemente ou não, tem garantido uma sustentação do número de escolas abaixo da média mesmo face a elevação anual da meta definida pela Secretaria:

Então a gente atendia, sei lá, 300 escolas que tinham desempenho abaixo de 2.6. Ok, então a gente melhorou o resultado geral. Aí a gente pega... escola prioritária não é mais quem tem desempenho abaixo de 2.6, abaixo de 2.8. Passamos de 2.8 pra três, de três pra 3.2, de 3.2 pra 3.4 e pra esse ano [2017], a régua é 3.5 que é a Média Brasil. E agora a gente tomou uma decisão estratégica e tem uma mensagem muito importante [...]. Nós estamos dizendo com essa mensagem que prioritário é que a gente quer tirar desse patamar a escola que tá abaixo da Média Brasil (Entrevista B1).

O mérito fundamental de conseguir manter um crescimento sustentável da média escolar por meio de uma estratégia de superar a média brasileira estaria em perceber um maior nível de igualdade entre as escolas por meio da minimização de lacunas dentro da própria rede. Dentro desse raciocínio, a possibilidade de dirigir ações voltadas à diminuição de tais lacunas apontam, no sistema de monitoramento por indicadores de resultados do PPE, um conjunto de instrumentos norteadores das ações do gestor, reforçando, pelo menos nesse sentido, que não se trata apenas "do número pelo número". Dentro dessa compreensão, a efetividade torna-se especialmente importante como indicador valorativo da gestão da política (Motta, 1972), na medida em que permite à mesma, para além da preocupação com metas, concentrar-se em garantir objetivos mais amplos de equidade de fruição dos serviços de educação em todas as escolas.

\subsection{A publicitação do desempenho escolar e dos resultados do PPE}

Ao passo que o trabalho com indicadores traga implicações importantes para o nível da gestão, a sua publicitação já tem reverberado sinais peculiares de efetividade da política pública a um nível ainda mais próximo da comunidade e do contexto escolar. Tais sinais emergem dadas as possibilidades objetivas de acesso a SIEPE, o qual permite o acompanhamento do desempenho discente pelos pais ou responsáveis e da disseminação dos resultados do PPE, visível nos painéis de gestão (onde ficam expostos os principais resultados da GRE) ou pela própria mídia, quanto à visibilidade dada aos resultados do IDEPE, principal indicador de resultados do Pacto.

A princípio, é possível afirmar que a possibilidade de acesso a um sistema integrado com todas as informações e indicadores trabalhados no Pacto trouxe para a rede um sentimento de maior credibilidade para a escola pública. Como um sinalizador importante para a efetividade da prestação de serviços educacionais, esse sentimento parte de uma percepção que se manifesta primariamente no trabalho dos próprios gestores, quando mencionam que "a escola pública era desacreditada", mas voltou a ser "acreditada". 
Muitos depoimentos em torno da questão da credibilidade também suscitaram comparações entre as escolas públicas e privadas, ressaltando essa possibilidade de acesso ao SIEPE como um ponto positivo em credibilidade para a escola pública. Tal sentimento de credibilidade também sinaliza como a inovação proporcionada pelo sistema permite à rede pública usufruir de possibilidades genuínas de modernização (Heidmann \& Salm, 2009), independentemente de qual seja sua configuração presente (Ramos, 1983), sem necessariamente recorrer a modelos externos (ou recuperados da rede privada).

$\mathrm{Na}$ ótica da gestão, a publicidade dos indicadores no SIEPE também implica objetivamente em mais transparência no serviço público. Esse sinalizador também representa para a comunidade escolar uma mudança cultural na forma de acompanhamento do discente, "quebrando barreiras" e encurtando o tempo de feedback sobre o desempenho no sistema escolar entre professores, pais e alunos. Tal perspectiva se mostra coerente com a visão das "possibilidades de desenvolvimento" pontuadas por Santos et al. (2015), as quais devem considerar estratégias que operem, pelo menos, sob três níveis, a saber: Indivíduo, organização e sociedade.

Ainda que nem todos os pais dos alunos se interessem ou tenham familiaridade com o acesso aos dados do SIEPE, outra implicação importante referente a essa possibilidade diz respeito a uma "percepção" de empoderamento por parte da comunidade escolar, em relação à preferência por uma determinada escola em detrimento de outra. Trata-se apenas de uma percepção, uma vez que ainda não implica em efetivo poder de escolha por parte da população. A universalização do acesso às escolas de tempo integral, por exemplo, ainda é objeto de interesse perseguido pela SEE-PE. Entretanto, a "percepção" da notoriedade do desempenho dessas escolas, bem como a capacidade da população para elencar escolas como "melhores” ou "piores”, gera na comunidade uma espécie de empoderamento em potencial. Pela ótica da gestão, essa percepção se faz latente mediante observação da disponibilidade de vagas para matrículas nas escolas com melhor desempenho, caso de muitas escolas de referência, como citado a seguir:

É... nós temos aqui em [...] uma Escola de Referência, a escola [...]. Hoje ela tem o melhor resultado do IDEPE do agreste. E está sem... está entre as dez melhores... Não é dez, não... entre as vinte melhores, se eu não me engano... do resultado geral... Então... de repente, isso foi pra mídia... e hoje eu não tenho uma vaga lá. Porque todos os pais querem que seu filho vá pra lá. Quando a gente diz que não tem, e que oferece outra escola, eles perguntam logo: E como é que tá o "resultado" dessa escola? Ele pode não saber que resultado... se é IDEPE, se é Ideb... isso eles não sabem... Mas e 'como é que tá o resultado' dessa escola? (Entrevista C.1).

Para outro respondente: "Agora a gente vê que a gente pode dizer a ele, 'ó, você quer ir pra essa, mas essa tirou quatro, não é melhor essa aqui que tá pertinho com cinco, pra seu filho?’, então a gente agora tem um parâmetro, está público aí, está público" (Entrevista B.4).

Uma abordagem em torno dos demais indicadores (que não o IDEPE) e sua publicitação se mostra, por fim, em uma das implicações talvez mais subjetivas, porém pertinentes pela perspectiva da gestão, em seus relatos sobre um nível mais aprofundado de conscientização pedagógica da população em relação ao próprio contexto escolar:

A gente já tem pai de família, quando a gente apresenta os resultados da escola, ele dá opinião, ele sabe por que, ele já se queixa da qualidade dos serviços de alguns profissionais. Ou então eles já dão visibilidade àqueles que se destacam, em dizer, "esse aqui não pode sair da nossa escola porque é um bom profissional”, em dizer, “essa escola a gente não quer...”, por exemplo, que se mude o tipo de oferta de ensino que ela tem porque ela dá bons resultados naquela oferta (Entrevista C.2).

Pelas reivindicações que chegam até a gestão, infere-se que a inclusão dessa discussão no âmbito das GREs já esboça uma maior preocupação popular em relação aos itens que, na verdade, nada mais são do que os indicadores de processo e descritores escolares. $\mathrm{O}$ aprofundamento de uma consciência também tem sido corroborado via participação da população nos Seminários Regionais, refletido por meio de demandas que começam a se referir ao sistema pedagógico escolar, como nos casos em que a população pede que não se municipalize a escola, ou se refira à "qualidade" do serviço prestado. Nos termos em que 
apresenta Ramos (1983b), assim se constitui o "desenvolvimento das possibilidades", quando avaliado como modalidade que vai além do indivíduo e se pauta sobretudo na coletividade em questão, considerando seus fatores limitantes e inovadores. Conforme depoimento de um dos Secretários de Educação entrevistados, o PPE começou a pensar em educação de uma forma muito pragmática: "Vamos melhorar o prédio, vamos melhorar a infraestrutura, vamos melhorar a merenda, vamos ter livro, aquele pacote básico que constitui o serviço" (Entrevista B.3). Com o decorrer dos anos, porém, os gestores têm relatado menos reivindicações relacionadas a elementos como merenda ou infraestrutura da escola e mais reivindicações por qualidade, ainda que esse pedido não seja feito de forma direta, como mencionou outro depoente: "Dificilmente você vai ouvir obviamente uma pessoa da população que não conhece bem as ferramentas de gestão pedir 'olha, eu quero que vocês propaguem esse modelo de gestão' é muito improvável que isso aconteça em curto espaço de tempo. Mas nós escutamos coisas do tipo 'olha, eu não quero que municipalize a escola aqui no meu município"” (Entrevista A.3).

Assim, a publicitação dos resultados do PPE apresenta-se como possibilidade objetiva de mudança na medida em que permite uma dialética de participação e experimentação pela população. Adicionalmente, conforme reafirmado pela Teoria das Possibilidades, admite-se que é de forma incremental que acontece a compreensão de uma determinada realidade, exigindo, para tanto, relativa participação da sociedade na mesma (Ramos, 1983a). Dessa forma é que a gestão visualiza uma mudança de consciência referente à comunidade escolar, na medida em que outros aspectos relativos à forma de gerenciamento passam a ser mencionados pela população:

Então a população já não é mais só construir escola, recuperar escola, né? [...] mas já tem algumas discussões do tipo "olhe, vamos... por que não ampliar as Escolas de Tempo Integral?”, né? "Vamos fortalecer a Educação Profissional”, então já tem um... a população já tá mergulhando um pouco mais, entendendo um pouco mais a importância de algumas estratégias (Entrevista B.1).

Além de reforçar a ideia de que parte da população já começa a esboçar uma consciência pedagógica mais aprofundada em relação à que apresentava no período inicial ao Pacto, as discussões nos chamados Seminários Regionais contribuem para politizar o processo de planejamento, estratégia importante para a Administração para o Desenvolvimento (Martins, 2004). Outrossim, configuram-se como uma prática de gestão participatória, igualmente relevante para alcançar a referida efetividade na Administração Pública (Motta, 1972). Os Seminários, entretanto, funcionam como um canal mais amplo de diálogo do governo com a sociedade, com vistas à participação desta no processo de planejamento de políticas não apenas relativas à educação (SEPLAG, 2018).

A figura 1 esquematiza como as inovações do PPE descritas anteriormente podem configurar-se como "possibilidades objetivas" para o desenvolvimento. 


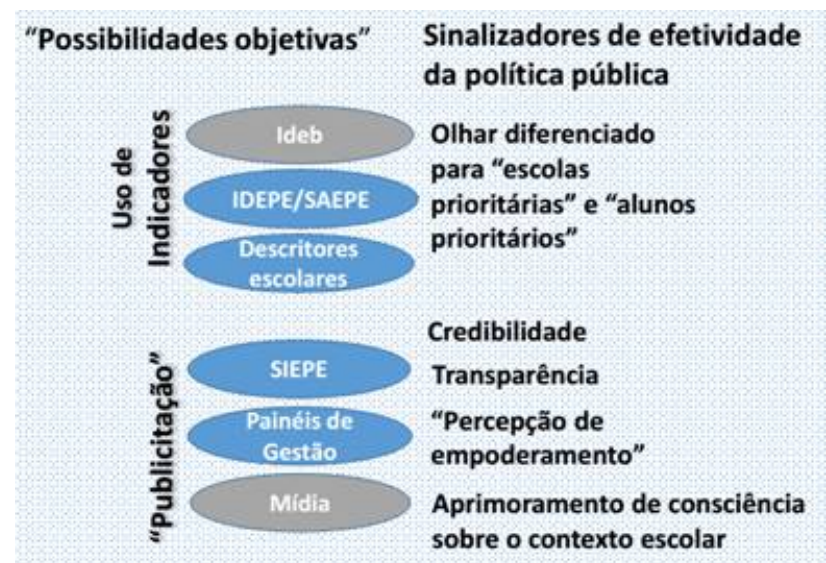

Figura 1. Inovações como possibilidades objetivas e seus sinalizadores de efetividade Fonte: Elaborado pela autora, 2019.

As práticas elencadas pelas categorias "uso de indicadores" e "publicitação" configuram-se como possibilidades objetivas exatamente por meio das inovações destacadas ao centro, para o caso do PPE, em azul: IDEPE (aferido por meio do SAEPE) e de descritores escolares, SIEPE e Painéis de Gestão expostos nas GREs. Os itens “Ideb” e "mídia” não constituem, naturalmente, peculiaridades do Pacto pela Educação em Pernambuco, mas, associados à tais práticas, ajudam a constituir essas possibilidades objetivas, e por isso foram integrados ao conjunto. Ao lado direito, sintetizam-se os principais sinalizadores identificados para cada categoria, detalhados ao longo da análise anteriormente exposta.

\section{CONSIDERAÇÕES FINAIS}

A princípio, é útil reconhecer, no que tange aos procedimentos metodológicos adotados nesta pesquisa, as restrições deste estudo ao campo da gestão e, naturalmente, às óbvias limitações em alcançar fontes primárias do grande universo ao qual pertence toda a comunidade escolar.

Neste trabalho, é válido destacar, ao longo da análise, a convergência de temas emergentes em torno do SIEPE como um dos principais instrumentos de publicitação dos indicadores do Pacto e do IDEPE. O SIEPE foi citado por quase todos os entrevistados como o instrumento de comunicação mais eficaz entre corpo docente, família dos alunos, escola e GRE, e pontuado como principal plataforma para a mudança de comportamento da comunidade escolar em relação à publicidade e à transparência dos resultados que estão sendo obtidos na educação. No entanto, alguns entraves como atrasos na alimentação do sistema e problemas na rede de internet fornecida nas escolas ainda dificultam e prejudicam a plenitude de seu aproveitamento.

Adicionalmente, propõe-se que, além de atentar para questões referentes a possíveis aspectos ligados à transversalidade dessa política junto a questóes técnicas (como na necessidade apontada de manutenção da rede de internet, por exemplo), sejam empenhados maiores esforços para a compreensão de como os estratos mais vulneráveis da população adquirem consciência dos desdobramentos mais significativos das estratégias traçadas pelo governo no início e ao longo de cada período de gestão. Em que pese sinalizadores como o olhar diferenciado para escolas e alunos prioritários e o aumento da credibilidade que vem sendo conferida à escola pública possam ser fortemente evidenciados como ganhos importantes do PPE em Pernambuco, nota-se que o aprimoramento da consciência sobre o contexto escolar constitui um sinalizador que ainda se encontra em um estágio incipiente de percepção em meio à comunidade.

Dessa forma, no mesmo sentido da necessidade de aprimoramento da consciência da comunidade em relação às estratégias traçadas pelo governo - não apenas no âmbito da educação -, sugere-se aqui que o aprimoramento da participação popular na elaboração das políticas públicas também se configure como 
um processo importante na identificação de possibilidades objetivas para o desenvolvimento. A ampliação da participação da comunidade por meio de tal ampliação de consciência, junto à ampliação de canais que fomentem uma aproximação à construção social da política pública certamente facilitarão, por sua vez, o reconhecimento, na gestão, de outras "possibilidades objetivas" para o desenvolvimento e dos sinalizadores de sua efetividade, por parte da própria população. Tal participação mostra-se sobremaneira importante em um contexto de mudança social deliberada, tal qual menciona Ramos (1966). Ainda mais quando o "diálogo com a sociedade" é uma das premissas apresentadas pelo Mapa da Estratégia do governo.

O contato direto da gestão com as demandas levantadas pela população nos Seminários Regionais, bem como as considerações e reivindicações feitas pela comunidade escolar no âmbito das GREs junto aos Gerentes - seja em momentos de matrícula ou em resposta a problemas pedagógicos destoantes dos indicadores validados pelo SIEPE - revela como a experiência de gestão tem muito a ganhar e a ser aprimorada pela via de construção coletiva da política pública, ou, pelo menos, por esforços de aproximação dessa como um modelo ideal.

Por fim, pontua-se que os requisitos originalmente definidos por Motta (1972) para uma nova Administração para o Desenvolvimento permanecem relevantes: Orientação para resultados, modelos orgânicos de gestão e comprometimento valorativo dos atores envolvidos (Martins, 2004). Diretamente ligado a esse modelo de gestão por resultados encontra-se o BDE, o qual constitui objeto importante para uma representação prática de novos modelos de gestão da remuneração ou sistemas de recompensa de colaboradores, e que, embora não reverbere sinalizadores mais perceptíveis junto à comunidade como os itens anteriormente analisados, merece ser ressaltado como prática interna de fundamental relevância de inovação estratégica para a gestão e também responsável pelo alcance de bons resultados que vem sendo obtidos no campo da educação.

Pela ótica do desenvolvimento das possibilidades, também seria plausível concluir que diversas estratégias de desenvolvimento se tornam efetivamente viáveis por meio de "possibilidades objetivas" que emergem da inovação. Sob esta perspectiva, faz sentido inferir que o estudo sobre práticas de inovação, mesmo que pela ótica da gestão, também permite lançar um olhar delicado para a realidade fora do contexto no qual ela se manifesta (no caso do PPE, para além do contexto escolar propriamente dito).

Como sugestão para pesquisas futuras, propõem-se investigações feitas pela ótica de estudantes ou dos próprios professores, em um foco que venha a maximizar a oportunidade de compreender diferentes posições de sujeitos e triangular os discursos sobre inovação na gestão.

\section{REFERÊNCIAS}

Arretche, M., Fuzaro, E. \& Gomes, S. (2012, agosto). Democracia, políticas sociais e pobreza no Brasil. Anais do Encontro ABCP, Gramado, RS, Brasil, 8.

Bardin, L. (1977). Análise de conteúdo. Lisboa: Edições 70 Ltda.

Bauer, M. W. \& Aarts, B. (2002). A construção do corpus: um princípio para a coleta de dados qualitativos. In Bauer, M. W. \& Gaskell, G., Pesquisa qualitativa com texto, imagem e som: um manual prático. Petrópolis, RJ: Vozes.

Bloch, C. (2010). Measuring public innovation in the Nordic Countries: Copenhagen Manual. MEPIN, Copenhagen, Denmark. Recuperado de http://nyskopunarvefur.is/files/filepicker/ 9/201102_mepin_report_web.pdf.

Blumer, H. (1969). Symbolic interactionism. Englewood Cliffs, NJ: Prentice-Hall.

Cavalcanti, A. C. D. (2011). Programa de modernização da gestão pública/ metas para a educação/ 2007-2010. (Dissertação de Mestrado). UFPB-CE. Programa de Pós-graduação em Educação, João Pessoa, PB, Brasil.

Charmaz, K. (2006). Constructing grounded theory: a practical guide through qualitative analysis. London: Sage.

Correia, M. S. (2011). Capacidade do núcleo estratégico na contratualização de resultados - análise da trajetória de Pernambuco. (Dissertação de Mestrado). FGV- Escola de Administração de Empresas de São Paulo. Mestrado em Administração Pública e Governo. São Paulo, SP, Brasil. 
Creswell, J. W. (2010). Projeto de pesquisa: métodos qualitativo, quantitativo e misto. 3. ed. Porto Alegre: Artmed/ Bookman.

Dias, I. M. (2014). Práticas de inovação em gestão pública. In Agune, R., Gregório, A., Neves, A., Dias, I. M., Carlos, J. A. \& Bolliger, S. (Orgs.). Dá pra fazer: Gestão do conhecimento e inovação no setor público. São Paulo: Secretaria de Planejamento e Desenvolvimento Regional.

Flick, U. (2013). Introdução à Metodologia de Pesquisa: um guia para iniciantes. Porto Alegre: Pensa.

Freire, P. Educação como prática da liberdade. São Paulo: Paz e Terra, 2000.

Godoy, A. S. (2006). Estudo de caso qualitativo. In Godoi, C. K., Bandeira-De-Melo, R. \& Silva, A. B. (Orgs.). Pesquisa qualitativa em estudos organizacionais: paradigmas, estratégias e métodos. São Paulo: Saraiva.

G1. (2016, setembro 8) Escolas públicas de PE lideram ranking nacional do ensino médio. Recuperado de http://g1.globo.com/pernambuco/educacao/noticia/2016/09/pernambuco-lidera-rankingnacional-do-ensino-medio-segundo-ideb.html.

Germano, B. N. (2015). Avaliação de impacto da política de gestão por resultados do Pacto pela Educação do governo do estado de Pernambuco. (Tese de Doutorado). Programa de Pós-graduação em Economia, UFPE - CCSA. Recife, PE, Brasil.

Gomes, R. A análise de dados em pesquisa qualitativa. In Deslandes, S. F., Cruz Neto, O., Gomes, R. \& Minayo, M. C. $S$ (org.) (1994). Pesquisa social: teoria, método e criatividade (16. ed., cap. 4). Petrópolis: Vozes.

Hamel, G. (2006). The why, what, and how of management innovation. Harvard business review, 84(2), p. 72.

Halvorsen, T. (2005). On innovation in the public sector. In Halvorsen, T., Hauknes, J., Miles, I. \& Roste, R. On the differences between public andprivate sector innovation. Nifu Step: Oslo.

Heidemann, F. G. \& Salm, J. F. O desenvolvimento ao alcance da política: modelos de possibilidade versus modelos de necessidade. In Heidemann, F. G. \& Salm, J. F. (Org.) \& Guimarães, T. A. (apresentação). Políticas públicas e desenvolvimento: bases epistemológicas e modelos de análise (pp. 21-22). Brasília: UnB, 2009.

Inep (2016). Brasil no Pisa 2015: Sumário Executivo. Recuperado de: http://download.inep.gov.br/ acoes_internacionais/pisa/documentos/2016/pisa_brasil_2015_sumario_executivo.pdf

Inep (2019). Índice de Desenvolvimento da Educação Básica - Resultados e Metas. Recuperado de: http:// ideb.inep.gov.br/resultado/resultado/resultadoBrasil.seam?cid=3111091.

Lemos, C. S. (2009). Gestão Pública orientada para resultados: avaliando o caso de Minas Gerais. (Dissertação de Mestrado). FGV- Escola Brasileira de Administração Pública e de Empresas. Centro de Formação Acadêmica e Pesquisa. Rio de Janeiro, RJ, Brasil.

Martins, H. F. (2004). Administração para o Desenvolvimento - a relevância em busca da disciplina. Governança e Desenvolvimento, $1(1)$.

Merriam, S. B \& Tisdell, E. J. (2016). Qualitative research: a guide to design and implementation. San Francisco: Jossey-Bass.

Motta, P. R. (1972). Administração para o Desenvolvimento: a disciplina em busca da relevância. Rev. Adm. Pública, Rio de Janeiro, 6 (3), 39-53.

Motta, P. R. \& Schmitt, V. G. H. (2013). Administração para o Desenvolvimento: a ideia e a renovação. Cadernos EBAPE.BR, 11 (2) 107-206.

Nery, M. F.; Peixoto, D. L. (2013). Mercados e racionalidades: a perspectiva de Alberto Guerreiro Ramos e Cornelius Castoriadis. Cadernos EBAPE.BR, 11 (4), 543-543.

Oliveira, M. S. M. (2014). Gestão e aprendizagem: evidenciando o Pacto pela Educação. (Dissertação de Mestrado). UFJF-Centro de Políticas Públicas e Avaliação da Educação. Programa de Pós-graduação Profissional em Gestão e Avaliação da Educação Pública, Juiz de Fora, MG, Brasil.

Patriota, C. M. P. E. (2014). Política de monitoramento e gestão por resultado: estudo de caso de uma escola de Pernambuco. (Dissertação de Mestrado). UFJF - Centro de Políticas Públicas e Avaliação da Educação. Programa de Pós-graduação Profissional em Gestão e Avaliação da Educação Pública, Juiz de Fora, MG, Brasil. 
Pernambuco. [n.d.]. Guias “Tecnologias na Escola”. SEE-PE. Recuperado de http://www.educacao.pe.gov.br/portal/? pag $=1 \&$ men $=146$.

Pernambuco. (2015). Relatório Anual de Ação do Governo. Recuperado de http://www.seplag.pe.gov.br/c/ publicador_revista/get_file?p_1_id $=27735 \&$ numero $=9 \&$ codigo $=410$.

Ramos, A. G. (1966). Administração e estratégia do desenvolvimento: elementos de uma sociologia especial da administração. Fundação Getúlio Vargas, Serviço de Publicações.

Ramos, A. G. (1981). A nova ciência das organizações: uma reconceituação da riqueza das nações. Rio de Janeiro: FGV.

Ramos, A. G. (1983a.). A modernização em nova perspectiva: em busca do modelo da possibilidade. Rev. Adm. Pública, 17(1), 5-31.

Ramos, A. G. (1983b). A nova ignorância e o futuro da Administração Pública na América Latina. Rev. Adm. Pública, $17(1), 32-65$.

Santiago, F. M. L. (2014). Educação e desenvolvimento em Pernambuco entre 2004 e 2014: Desvelando os nexos do Programa de Educação Integral com o rejuvenescimento da Teoria do Capital Humano. (Dissertação de Mestrado). UFPE-CAA. Programa de Pós-graduação em Educação Contemporânea, Caruaru, PE, Brasil.

Santos, E. L., Santos, R. S. \& Braga, V. (2015). Administração do Desenvolvimento na perspectiva Guerreirista: conceitos, contribuições e implicações. Cadernos EBAPE. BR, 1(1), 462-477.

SEE-PE. (2014). PE tem maior crescimento do Brasil no Ideb do ensino médio. Recuperado de http:// www.educacao.pe.gov.br/portal/?pag $=1 \&$ cat $=37 \&$ art $=2046$.

Sen, A. Desenvolvimento como liberdade. São Paulo: Companhia de Bolso, 2010.

SEPLAG. (2018). Todos por PE. Recuperado de seplag.pe.gov.br.

SIEPE. (2017). Índice de desenvolvimento da educação básica de Pernambuco-IDEPE. Recuperado de http://www.siepe.educacao.pe.gov.br/WebModuleSme/itemMenuPagina ConteudoUsuarioAction.do? action Type $=$ mostrar\&idPaginaItemMenuConteudo $=5911$.

Thompson, V. (1964). Administrative objectives for development administration. Administrative Science Quarterly, 9, 108.

Yin, R. K. (2005). Estudo de caso: planejamento e métodos. 3. ed. Porto Alegre: Bookman.

\section{Notas}

[i] Em 2013, antecipou em dois anos as metas projetadas pelo MEC para o período. Também conquistou posição de liderança no ranking nacional de menor taxa de abandono escolar do Brasil nos anos de 2013 e 2014 (SEE-PE, 2014). Em relação aos resultados do Ideb divulgados para o ano de 2015, ficou entre os cinco estados que cumpriram a meta prevista para os anos finais do Ensino Fundamental e entre os dois únicos estados brasileiros que cumpriram a meta para o Ensino Médio. Ainda nesse ano, as escolas públicas pernambucanas colocaram o estado, juntamente com o estado de São Paulo, na posição de liderança no ranking nacional para o índice do Ideb $(G 1,2016)$.

[ii] O Programa Internacional de Avaliação de Estudantes (Pisa), ou Programme for International Student Assessment, é uma iniciativa de avaliação comparada dos níveis de proficiência nas áreas de Ciências, Leitura e Matemática, aplicada de forma amostral a estudantes matriculados a partir do $7^{\circ}$ ano do ensino fundamental na faixa etária dos 15 anos. É coordenado pela Organização para Cooperação e Desenvolvimento Econômico (OCDE) com o apoio de uma coordenação nacional em cada país participante.

[iii] O "Todos por Pernambuco" é fruto de uma mudança nos moldes de gestão estadual, com a implementação do modelo de Gestão Pública por Resultados - iniciado no Governo Eduardo Campos em Pernambuco, a partir de 2007.

[iv] A opção de considerar o acúmulo de crescimento percentual desde o momento da implementação do Modelo de Gestão Integrada “Todos por Pernambuco", em 2008, justifica-se pelo fato de já iniciarem, nesse período, algumas ações de monitoramento do trabalho nas GRE's e políticas voltadas à preparação de um contexto propício para colocar em prática o PPE, com o planejamento das ações que serviriam de base para o seu lançamento oficial em 2011.

\section{BY-NC-ND}

